\title{
STRATEGI SI/TI DALAM PENINGKATAN MUTU RUMAH SAKIT MENGGUNAKAN ANALISIS BUSINESS STRATEGY DAN VALUE CHAIN
}

\author{
Kamarudin $^{1}$ \\ ${ }^{1}$ Fakultas Teknik, Universitas Muhammadiyah Banjarmasin \\ kamarudin@umbjm.ac.id
}

\begin{abstract}
The low value of accreditation based on the quality accreditation results from KARS 2012, RSUD Datu Sanggul Rantau which is the object of this research is at a 1: 5 star rating with first graduated status. This study aims to develop a Strategic Information System and Information Technology Concept which is used as a reference for the development of IS / IT in improving the quality of the Datu Sanggul Rantau Regional General Hospital in Kab. Tapin South Kalimantan. This study uses a business strategy and value chain analysis approach. The study was conducted by conducting in-depth interviews with users, hospital staff, department heads and hospital heads, as well as observation and document review. RSUD Datu Sanggul Rantau has implemented SIMRS to support services to patients. The condition of the existing information system, there is still a need to develop the existing application modules, add human resources to manage SIM, increase user knowledge through training, there is no special field that handles IS / IT, IS / IT SOP does not exist, there is no IS strategy concept /TI .. This research provides a report that is focused only on the Datu Sanggul Rantau Hospital.
\end{abstract}

Keywords: IS/IT Strategy, Business Strategy, Value Chain, Hospital Quality

\begin{abstract}
Abstrak
Rendahnya nilai akreditasi berdasarkan kualitas hasil akreditasi KARS 2012 RSUD Datu Sanggul Rantau yang menjadi objek penelitian ini berada pada peringkat bintang 1: 5 dengan status lulus pertama. Penelitian ini bertujuan untuk mengembangkan Sistem Informasi Strategis dan Konsep Teknologi Informasi yang dijadikan acuan pengembangan SI / TI dalam meningkatkan kualitas RSUD Datu Sanggul Rantau Kab. Tapin Kalimantan Selatan. Penelitian ini menggunakan pendekatan strategi bisnis dan analisis rantai nilai. Penelitian dilakukan dengan melakukan wawancara mendalam dengan pengguna, staf rumah sakit, kepala departemen dan kepala rumah sakit, serta observasi dan telaah dokumen. RSUD Datu Sanggul Rantau telah menerapkan SIMRS untuk mendukung pelayanan kepada pasien. Kondisi sistem informasi yang ada, masih perlu mengembangkan modul aplikasi yang sudah ada, menambah SDM untuk mengelola SIM, menambah pengetahuan pengguna melalui pelatihan, belum ada bidang khusus yang menangani SI / TI, SOP SI / TI tidak tidak ada konsep strategi SI / TI .. Penelitian ini memberikan laporan yang difokuskan hanya pada RSUD Datu Sanggul Rantau..
\end{abstract}

Keywords: Strategi SI / TI, Strategi Bisnis, Rantai Nilai, Kualitas Rumah Sakit

\section{PENDAHULUAN}

Sistem informasi di sebuah organisasi besar seperti rumah sakit dapat memberikan dukungan informasi kepada semua tingkat administrasi pelayanan dengan data yang valid, akurat dan lengkap, serta dapat diakses dengan mudah, cepat dan dengan jangkauan uang luas. Rumah sakit membutuhkan rencana strategis agar mampu menempatkan dirinya pada posisi yang tepat agar dapat mengatasi persaingan. Dengan adanya rencana strategi sistem informasi dan teknologi informasi (strategi SI/TI) untuk dapat menerapkan dan memanfaatkan sumber daya organisasi secara optimal, pengembangan SI/TI terarah berdaya guna dan berhasil guna dalam mencapai sasaran yang diinginkan [1], namun sebaliknya ketika di sebuah rumah sakit tidak memiliki rencana strategi SI/TI mengakibatkan pengembangan sistem informasi dilakukan tidak terarah, prioritas pengembangan SI/TI tidak sama dengan prioritas bisnis, tidak ada target dan tidak ada tahapan dalam pengembangan TI, platform teknologi kurang terarah sehingga menyulitkan pengembangan sistem informasi. Rencana strategis idealnya dilakukan dengan pendekatan partisipatif dimana setiap staf bagian SI/TI terlibat dalam penyusunannya. Strategi SI/TI akan memberikan panduan secara umum dalam membangun dan mengembangkan sistem informasi rumah sakit pada masa yang akan dating [2]. Strategi SI/TI dibuat dengan mengacu pada kondisi yang ada pada saat ini dan kondisi dinamis lingkungan global [3]. Perancangan strategis menjawab tiga pertanyaan yaitu dimanakah posisi organisasi saat ini, ke mana 
dan kapan akan mencapai tujuan, serta bagaimana cara mencapai tujuan [4]. Keterlibatan pengguna, manfaat, proses, dukungan dan kepemimpinan merupakan hal paling penting [5]. Strategi SI/TI yang akan dibuat harus diselaraskan dengan rencana strategi rumah sakit, yang nantinya akan digunakan oleh rumah sakit sebagai acuan proses pengambil keputusan manajemen rumah sakit dalam peningkatan mutu rumah sakit.

\section{Strategi Bisnis}

Barney (1997) menyatakan bahwa strategi adalah pola alokasi sumber daya yang memungkinkan organisasi-organisasi dapat mempertahankan kinerjanya [6]. Sedangkan Cannon (2008) mendefinisikan strategi sebagai adaptasi atas kebiasaan atau struktur dengan menguraikan dan menciptakan rencana yang sistematis dari yang akan dilakukan [7].

Strategi juga dapat didefinisikan sebagai suatu rangkaian kegiatan yang terintegrasi dan ditujukan untuk meningkatkan faktor-faktor yang menentukan tujuan dan kemampuan perusahaan [8].

Selain definisi yang telah disebutkan diatas berkenaan dengan sumber daya dan produk yang dihasilkan agar menjadi keunggulan yang bersaing [9], terdapat 2 jenis dasar competitive advantage untuk menjadikan perusahaan maju yaitu low cost dan differentiation dan dengan dasar ini strategi generik menghasilkan 3 strategi yaitu cost leadership, differentiation, dan focus. Disertai dengan pengembangan dari focus yaitu low cost focus dan differentiation focus. Perusahaan dapat memilih untuk menjadi lebih baik dengan menerapkan teori-teori diatas, sesuai dengan misi yang ingin dicapai.

\section{Value Chain}

Analisis Value Chain (rantai nilai) menggambarkan kegiatan yang berlangsung dalam bisnis dan menghubungkannya dengan analisis kekuatan kompetitif dari sebuah bisnis. Michael Porter menyarankan bahwa kegiatan bisnis dapat dikelompokkan dalam dua aktivitas, yaitu:

1. Aktivitas primer; semua aktivitas yang berkaitan dengan proses produksi maupun deliverinya, misal perakitan komponen.

2. Aktivitas pendukung; semua aktivitas yang tidak terlibat dalam proses produksi secara langsung namun dapat meningkatkan efektifitas maupun efisiensi, misal manajemen personalia.

Analisis Rantai Nilai adalah salah satu cara untuk mengidentifikasi aktivitas apa saja yang terbaik dilakukan oleh perusahaan dan mana yang lebih baik diberikan pada pihak lain (outsource) [9].

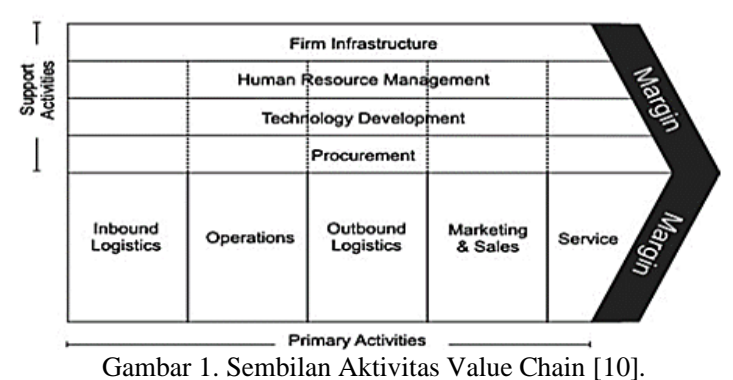

Berkenaan dengan perancangan strategi SI/TI dalam sebuah organisasi, maka organisasi Rumah Sakit Umum Daerah (RSUD) Datu Sanggul Rantau Kab. Tapin yang terletak di provinsi Kalimantan Selatan akan menjadi bagian objek utama penelitian ini, dalam rangka peningkatan mutu pelayanan organisasi kepada masyarakat di bidang kesehatan baik dari segi perawatan maupun pengobatan.

RSUD Datu Sanggul adalah rumah sakit negeri kelas C. Rumah sakit ini mampu memberikan pelayanan kedokteran spesialis terbatas. Rumah sakit ini juga menampung pelaynan rujukan dari puskesmas. Tersedia 80 tempat tidur inap, lebih sedikit dibandingkan setiap rumah sakit di Kalimantan Selatan yang tersedia rata-rata 88 tempat tidur inap, 29 dari 80 tempat tidur di rumah sakit ini berkelas VIP ke atas. Dengan 10 dokter, rumah sakit ini tersedia lebih sedikit dibandingkan rata-rata di Kalimantan Selatan.

Kementerian Kesehatan Republik Indonesia mewajibkan dilaksanakannya akreditasi rumah sakit dengan tujuan untuk meningkatkan mutu pelayanan rumah sakit di Indonesia. Dasar hukum pelaksanaan akreditasi rumah sakit adalah UU No.36 tahun 2009 tentang kesehatan, UU No. 44 tahun 2009 tentang rumah sakit dan Permenkes 1144/Menkes/Per/VIII/2010 tentang organisasi dan tata kerja kementerian Kesehatan. Akreditasi mengandung arti suatu pengakuan yang diberikan pemerintah kepada rumah sakit karena telah memenuhi standard yang ditetapkan. Rumah sakit yang telah terakreditasi, mendapat pengakuan dari pemerintah bahwa semua hal yang ada di dalamnya sudah sesuai dengan standar. Sarana dan prasarana yang dimiliki rumah sakit, sudah sesuai standar. Prosedur yang dilakukan kepada pasien juga sudah sesuai dengan standar [11].

Komite Akreditasi Rumah Sakit (KARS), lihat Gambar.2 mengembangkan standar akreditasi versi 2012. Standar ini lebih berfokus pada pasien; kuat dalam proses, output dan outcome; kuat pada implementasi serta melibatkan seluruh petugas dalam proses akreditasinya. Dengan adanya perbaikan ini diharapkan rumah sakit yang lulus proses akreditasi versi 2012 ini benar-benar dapat 
meningkatkan mutu pelayanannya dengan lebih berfokus pada keselamatan pasien [11].

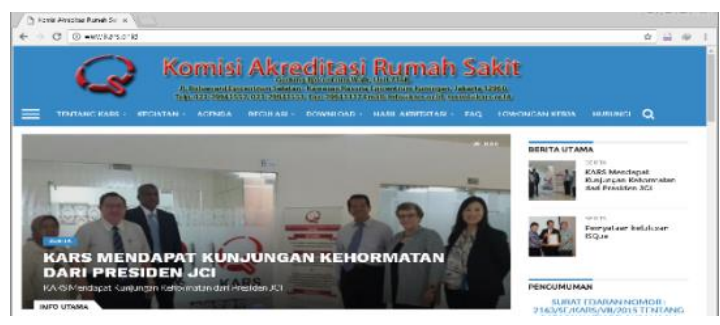

Gambar 2. Komisi Akreditasi Rumah Sakit (KARS)

Berdasarkan hasil akreditasi mutu dari KARS 2012, RSUD Datu Sanggul Rantau berada pada rating bintang 1:5 dengan status Lulus Perdana. Di bawah ini adalah gambar daftar rumah sakit teraktriditasi versi 2012.

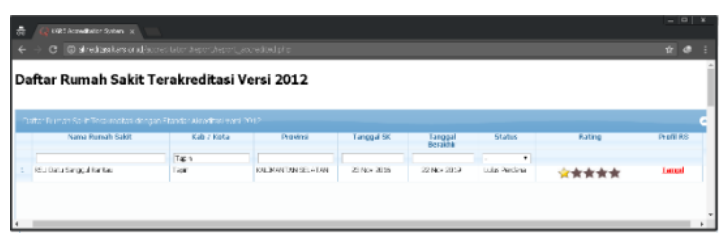

Gambar 3. Daftar Rumah Sakit Terakreditasi KARS 2012 [12].

Berbagai kegiatan akreditasi (KARS) dilaksanakan oleh RSUD Datu Sanggul Rantau untuk peningkatan mutu rumah sakit. Diikuti oleh beberapa elemen karyawan rumah sakit yang tergabung dalam kelompok kerja (pokja), diantaranya adalah pokja keperawatan, pokja pelayanan rekam medik dan administrasi manajemen, pokja pelayanan gawat darurat.

RSUD Datu Sanggul telah menggunakan aplikasi Sistem Informasi Manajemen Rumah Sakit (SIMRS). Dari aplikasi ini semua aktivitas pasien mulai dari proses registrasi sampai dengan farmasi sudah terintegrasi, namun hingga sekarang belum ada Standar Operasional Prosedur (SOP), blueprint infrastruktur maupun rancangan strategis SI/TI di rumah sakit tersebut. Sistem informasi rumah sakit berjalan begitu saja tanpa ada acuan yang jelas sehingga target dan tahapan pengembangan TI-nya kurang jelas, padahal dengan adanya rancangan strategi SI/TI semua hal terkait sistem informasi yang dijalankan akan lebih terarah dan sistematis yang nantinya dapat digunakan oleh pihak organisasi untuk pengembangan sistem informasi. Selain itu, dengan rancangan strategi SI/TI akan memudahkan bagi manajemen organsasi menjadikan acuan dalam proses pengambilan keputusan baik hal yang terkait internal maupun eksternal rumah sakit.

\section{METODE PENELITIAN}

Penting memaparkan latar belakang dari penelitian ini agar dapat menjadi pijakan awal untuk menemukan masalah yang dihadapi, kemudian dirumuskan permasalahan yang akan menjadi fokus penelitian. Setelah merumuskan pertanyaan penelitian, ditetapkanlah tujuan penelitian agar penelitian yang dilakukan dapat terarah. Selanjutnya menetapkan manfaat penelitian berupa kontribusi penelitian yang dibutuhkan bagi pengembangan ilmu pengetahuan, keilmuan, bagi masyarakat, dan bisnis sehingga dapat digunakan untuk penelitian selanjutnya.

Studi literatur dilakukan dengan cara mengumpulkan data penunjang mengenai teoriteori yang mendukung penelitian, penelitian terkait, serta metode yang banyak digunakan untuk dijadikan acuan dalam penelitian ini. Proses wawancara dan observasi dilakukan demi untuk mendapatkan data secara langsung di objek penelitian yaitu di Rumah Sakit Datu Sanggul Rantau.

Penelitian ini adalah penelitian kualitatif melalui pendekatan studi kasus dengan perspektif kajian sistem informasi. Alasan menggunakan pendekatan kualitatif karena peneliti bermaksud memahami situasi startegi SI/TI secara mendalam, menemukan pola, dan menggali lebih luas implikasi dari strategi SI/TI. Penelitian dilakukan di RSU Datu Sanggul Rantau Kab.Tapin. Penelitian dilakukan kurang lebih selama 3 bulan. Dan untuk informan penelitian yang dipilih adalah Kepala Rumah sakit, Kepala Bagian dan pegawai rumah sakit terkait penelitian ini.

Penilitian ini menggunakan 2 pendekatan analisis yaitu :

- $\quad$ Analisa Business Strategy. Pada bagian ini dilakukan analisa terhadap visi dan misi dari Rumah Sakit Datu Sanggul agar dapat diketahui secara dasar mengenai rancangan strategi bisnis rumah sakit.

- Analisis value chain, menggambarkan kegiatan di dalam Rumah Sakit Datu Sanggul dan sekelilingnya dan menghubungkan kegiatankegiatan tersebut ke dalam analisis kekuatan organisasi yang kompetitif.

\section{HASIL DAN PEMBAHASAN}

\section{Analisis Strategi Bisnis}

Arah dan tujuan bisnis rumah sakit Datu Sanggul Rantau dalam menghadapi persaingan yang kompetitif terlihat dalam visi, misi dan nilainilai perusahaan yang telah ditetapkan oleh manajemen. Untuk mewujudkan visi dan misi rumah sakit Datu Sanggul Rantau, maka disusunlah struktur organisasi yang berbentuk organisasi fungsional. 
Untuk melihat keberhasilan yang sudah dicapai oleh rumah sakit Datu Sanggul Rantau atas strategi yang sudah dicanangkan, dapat dilihat pada tabel berikut ini:

Tabel 1. Capaian Strategi yang sudah Dicanangkan

\begin{tabular}{|c|c|c|c|}
\hline No & Strategi & Target & Capaian \\
\hline 1 & $\begin{array}{l}\text { Penyediaan jasa } \\
\text { komunikasi, } \\
\text { sumber daya air } \\
\text { dan listrik }\end{array}$ & $100 \%$ & $80 \%$ \\
\hline 2 & $\begin{array}{l}\text { Penyediaan alat } \\
\text { tulis kantor }\end{array}$ & $100 \%$ & $80 \%$ \\
\hline 3 & $\begin{array}{l}\text { Penyediaan jasa } \\
\text { pegawai tidak } \\
\text { tetap (PTT) }\end{array}$ & $100 \%$ & $80 \%$ \\
\hline 4 & $\begin{array}{l}\text { Penyewaan sewa } \\
\text { rumah dokter } \\
\text { spesialis }\end{array}$ & $100 \%$ & $80 \%$ \\
\hline 5 & $\begin{array}{l}\text { Peningkatan } \\
\text { manajemen aset } \\
\text { daerah }\end{array}$ & $100 \%$ & $80 \%$ \\
\hline 6 & $\begin{array}{l}\text { Penyusunan } \\
\text { laporan keuangan } \\
\text { semesteran dan } \\
\text { akhir tahun }\end{array}$ & $100 \%$ & $80 \%$ \\
\hline 7 & $\begin{array}{l}\text { Penyediaan biaya } \\
\text { operasional dan } \\
\text { pemeliharaan } \\
\text { kebersihan }\end{array}$ & $100 \%$ & $75 \%$ \\
\hline 8 & Tapin EXPO & $100 \%$ & $75 \%$ \\
\hline 9 & $\begin{array}{l}\text { Pengadaan } \\
\text { peralatan } \\
\text { kesehatan }\end{array}$ & $100 \%$ & $80 \%$ \\
\hline 10 & $\begin{array}{l}\text { Kegiatan } \\
\text { pengadaan mobil } \\
\text { ambulance }\end{array}$ & $100 \%$ & $100 \%$ \\
\hline 11 & $\begin{array}{l}\text { Kegiatan } \\
\text { pengadaan } \\
\text { percetakan adm }\end{array}$ & $100 \%$ & $66,67 \%$ \\
\hline
\end{tabular}

\begin{tabular}{llll}
\hline \multicolumn{2}{c}{ dan surat } & & \\
& menyurat RS & & \\
\hline 12 & Penyelenggaraan & $100 \%$ & $80 \%$ \\
& BLUD RSUD & & \\
& Datu Sanggul & & \\
\hline
\end{tabular}

Capaian ini akan menggambarkan sejauh mana rumah sakit telah berusaha mewujudkan strategi yang telah dicanangkan. Segala kekurangan yang ditunjukkan dari capaian akan dievaluasi dan akan dilakukan usaha peningkatan yang berkesinambungan.

Untuk menggambarkan bagaimana hasil analisa strategi bisnis rumah sakit Datu Sanggul Rantau berdasarkan dari strategi yang sudah dicanangkan ditunjukkan pada tabel 2 berikut ini.

Tabel 2. Hasil Analisa Business Strategy Rumah Sakit

\begin{tabular}{|c|c|}
\hline KODE & HASIL ANALISA \\
\hline BS1 & $\begin{array}{l}\text { Struktur organisasi berbentuk } \\
\text { fungsional }\end{array}$ \\
\hline BS2 & $\begin{array}{l}\text { Memiliki program inovatif untuk } \\
\text { efisiensi biaya }\end{array}$ \\
\hline BS3 & $\begin{array}{l}\text { Jobdesk sesuai dengan fungsinya } \\
\text { masing-masing }\end{array}$ \\
\hline BS4 & $\begin{array}{l}\text { Rumah sakit mendukung } \\
\text { penyediaan jasa komunikasi, } \\
\text { sumber daya air dan listrik }\end{array}$ \\
\hline BS5 & $\begin{array}{l}\text { Rumah sakit mendukung } \\
\text { penyediaan alat tulis kantor }\end{array}$ \\
\hline BS6 & $\begin{array}{l}\text { Rumah sakit mendukung } \\
\text { penyediaan jasa pegawai tidak tetap }\end{array}$ \\
\hline BS7 & $\begin{array}{l}\text { Rumah sakit mendukung } \\
\text { penyewaan sewa rumah dokter } \\
\text { spesialis }\end{array}$ \\
\hline BS8 & $\begin{array}{l}\text { Rumah sakit telah mencanangkan } \\
\text { peningkatan manajemen aset daerah }\end{array}$ \\
\hline BS9 & $\begin{array}{l}\text { Rumah sakit telah mencanangkan } \\
\text { penyusunan laporan keuangan } \\
\text { semesteran dan akhir tahun }\end{array}$ \\
\hline BS10 & $\begin{array}{l}\text { Rumah sakit mendukung } \\
\text { penyediaan biaya operasional dan } \\
\text { pemeliharaan kebersihan }\end{array}$ \\
\hline
\end{tabular}




\begin{tabular}{ll}
\hline BS11 & Rumah sakit telah berhasil \\
& mengadakan promosi di Tapin \\
& EXPO \\
\hline BS12 & Rumah sakit telah berhasil dalam \\
& pengadaan peralatan kesehatan \\
\hline BS13 & Rumah sakit telah mencanangkan \\
& kegiatan pengadaan mobil \\
& ambulance \\
\hline BS14 & Rumah sakit telah mencanangkan \\
& kegiatan pengadaan percetakan adm \\
& dan surat menyurat rumah sakit \\
\hline BS15 & Rumah sakit telah berhasil \\
& menyelenggarakan BLUD RSUD \\
& Datu Sanggul Rantau \\
\hline
\end{tabular}

\section{Analisis Value Chain}

Dari struktur organisasi dan tugas pokok yang sudah dipaparkan, maka disusunlah analisa value chain untuk memetakan secara detail aktifitas yang ada pada rumah sakit Datu Sanggul Rantau. Setelah dipetakan akan dianalisa nilai positif apa yang sudah dihasilkan, nilai negatif apa yang harus dievaluasi, tentunya dengan bantuan sistem dan teknologi informasi.

Untuk mendeskripsikan beban tanggung jawab yang dimiliki oleh tiap unit dalam melaksanakan fungsinya pada 12 layananan instalasi perlu dicari kesesuaian dengan menggunakan RACI chart (www.ilmumanajemenindustri.com). Hal ini digunakan untuk pengambilan keputusan dan membantu pihak manajemen dalam mengidentifikasikan peran dan tanggung jawab karyawannya. Pembagian tugas yang jelas beserta peran dan tanggung jawabnya merupakan hal yang penting dalam suatu organisasi. Ketidakjelasan peran dan tanggung jawab akan menyebabkan kebingungan yang akhirnya akan mengakibatkan berkurangnya produktivitas kerja karyawannya.

Tanggung jawab yang digambarkan dalam RACI chart dapat dijelaskan sebagai berikut:

- $\quad \mathrm{R}$ (Responsible) : Orang yang melakukan suatu kegiatan atau melakukan pekerjaan.

- A (Accountable) : Orang yang akhirnya bertanggungjawab dan memiliki otoritas untuk memutuskan suatu perkara

- $\quad \mathrm{C}$ (Consulted) : Orang yang diperlukan umpan balik atau sarannya dan berkontribusi akan kegiatan tersebut

- I (Informed) : Orang yang perlu tahu hasil suatu keputusan atau tindakan
Pada tabel di bawah ini dapat dilihat unit mana saja yang bertanggungjawab terhadap layanan instalasi sesuai dengan porsinya masing-masing dalam tiap layanannya.

Tabel 3. RACI chart Rumah Sakit Datu Sanggul Rantau

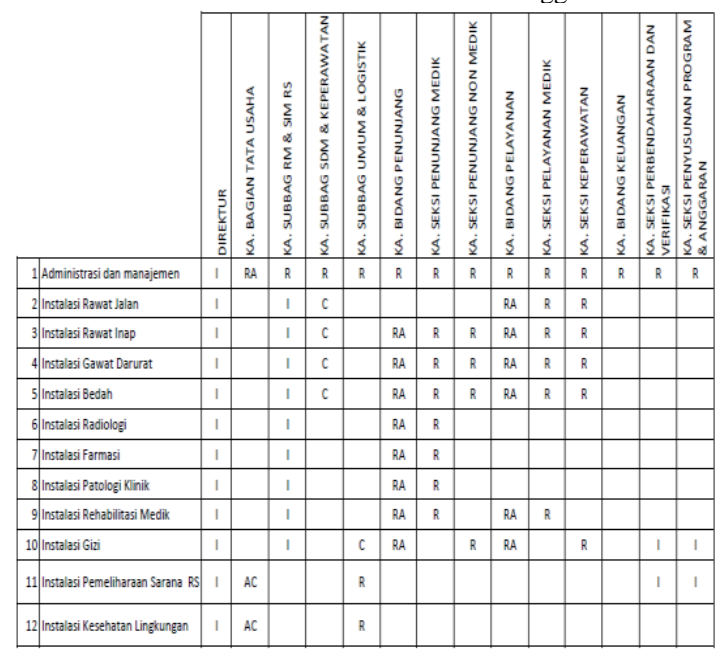

Adapun mapping ke dalam diagram value chain-nya dapat dilihat pada gambar di bawah ini. Aktifitas yang ada di tubuh rumah sakit terbagi menjadi dua aktifitas, yaitu aktifitas utama dan aktifitas pendukung.

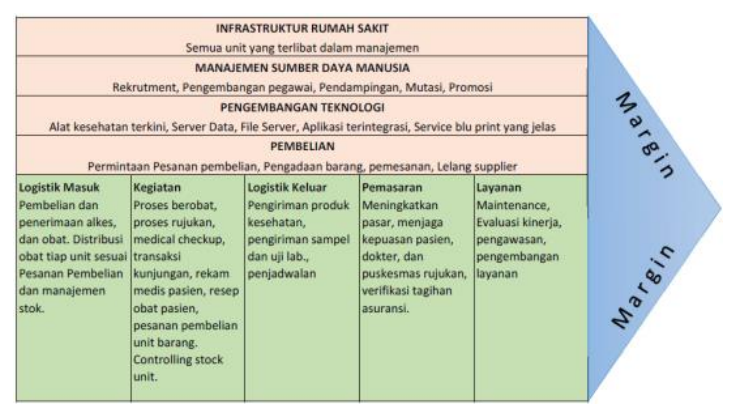

Gambar 4. Value Chain Rumah Sakit Datu Sanggul Rantau

Berikut ini adalah tabel hasil analisis value chain terhadap Rumah Sakit Datu Sanggul Rantau.

Tabel 4. Hasil Analisa Value Chain Rumah Sakit Datu Sanggul Rantau

\begin{tabular}{ll}
\hline Kode & Hasil Analisa \\
\hline VC1 & Manajemen stok yang kurang tertata \\
\hline VC2 & Proses pembelian melalui lelang dan \\
& penunjukan langsung \\
\hline VC3 & Kecepatan rekam medis dalam \\
& update rekam medis yang dirasa \\
& kurang
\end{tabular}




\begin{tabular}{|c|c|}
\hline VC4 & $\begin{array}{l}\text { Input data rekam medis yang sering } \\
\text { tertunda oleh sebagian unit }\end{array}$ \\
\hline VC5 & $\begin{array}{l}\text { Tidak semua bagian manajemen } \\
\text { menggunakan SIMRS walau sudah } \\
\text { terpasang/terhubung }\end{array}$ \\
\hline VC6 & $\begin{array}{l}\text { Pesanan pembelian barang unit telah } \\
\text { sesuai }\end{array}$ \\
\hline VC7 & $\begin{array}{l}\text { Pesanan pembelian barang unit yang } \\
\text { sering terlambat datang akibat } \\
\text { pending oleh vendor karena hutang } \\
\text { rumah sakit yang masih menunggak }\end{array}$ \\
\hline VC8 & $\begin{array}{l}\text { Belum tersedianya blueprint SI/TI } \\
\text { rumah sakit }\end{array}$ \\
\hline VC9 & $\begin{array}{l}\text { Integrated HRIS dengan training } \\
\text { belum ada }\end{array}$ \\
\hline VC10 & Asset Manajemen kurang terjaga \\
\hline VC11 & $\begin{array}{l}\text { Sistem pendampingan kompentensi } \\
\text { perawat sudah dilaksanakan namum } \\
\text { kurang optimal }\end{array}$ \\
\hline
\end{tabular}

\section{SIMPULAN DAN SARAN}

\section{A. Kesimpulan}

Berikut ini adalah kesimpulan dari hasil penelitian yang telah dilakukan:

1. Penelitian ini menggunakan pendekatan studi kasus pada metode kualitatif, sehingga dapat memberikan detail informasi dan validasi keabsahan yang lebih baik. Penelitian ini kurang cocok jika menggunakan metode kuantitatif, dikarenakan memiliki sampel yang beragam, lintas sektoral dan lintas fungsional dari sumber informan/responden yang ada.

2. Menggunakan metode penelitian terstruktur yang jelas dan dengan tahapan urutan yang tepat, maka penelitian ini dapat diselesaikan dengan tepat waktu dan lebih tepat sasaran.

3. Perlunya pendefinisan model konseptual, analisa domain dan definisi elemen dalam domain di kerangka konseptual atau model penelitian. Hal ini tentunya akan memudahkan proses pengumpulan data secara akurat selama penelitian berlangsung.

Pemahaman kondisi rumah sakit Datu Sanggul Rantau saat ini yang berkaitan dengan analisa lingkungan internal bisnis yang tertuang dalam visi dan misi rumah sakit serta strategi rumah sakit yang disusun. Struktur organisasi sejauh ini telah mampu menjalankan fungsinya, walaupun belum sepenuhnya mengakomodasi kebutuhan struktural dari fungsi-fungsi yang berkaitan dengan SI/TI rumah sakit. Hal ini setelah dilakukan analisa lanjutan berkenaan dengan lingkungan eksternal bisnis, dan lingkngan internal / eksternal SI/TI rumah sakit.

\section{B. Saran}

Adapun saran-saran untuk penelitian ini adalah :

1. Dikarenakan rekomendasi yang dihasilkan dari penelitian ini tidak mempertimbangkan biaya dan keuntungan, maka perlu perbaikan proses bisnis dan SI/TI serta aplikasi-aplikasi yang menjadi prioritas untuk dikembangkan di masa akan datang.

2. Lakukanlan analisa terhadap faktor-faktor yang menjadi prioritas pengembangan sistem informasi yang disertai analisa kelayakan investasi terhadap aplikasi maupun infrastruktur yang mendukung.

3. Untuk menentukan analisa strategi manajemen SI, strategi TI dan strategi bisnis SI/TI, terlebih dahulu dilakukan analisa efektifitas dan efisiensi dari strategi yang sudah ada, agar dalam penentuan hasil analisa menjadi lebih baik lagi.

\section{DAFTAR PUSTAKA}

[1] Subli, "Rencana Strategis Sistem Informasi Studi Kasus RSUD Dr. M. Yunus Bengkulu," Universitas Gadjah Mada, Yogyakarta, 2008.

[2] B. Brigl, E. Ammenwerth, C. Dujat, S. Graber, A. Grobe, and A. Haber, "Preparing Strategic Information Management Plans for Hospitals: a Practical Guuideline SIM Plans for Hospital: A Guideline," Med. Informatc, vol. 74, pp. 51-56, 2005.

[3] Kementerian Komunikasi dan Informatika, "Rencana Strategis Kementerian Komunikasi dan Informatika 2010-2014," 2010.

[4] M. Allison and J. Kaye, Perencanaan Strategis Bagi Organisasi Nirlaba: Pedoman Praktis \& Buku Kerja (terjemahan). Jakarta: Yayasan Obor Indonesia, 2004.

[5] K. Cresswell and A. Sheikh, "Organizational issues in the implementation and adoption of health information technology innovations: An interpretative review," Int. J. Med. Inf., vol. 82, no. 5, pp. e73-e86, 2013, doi: 10.1016/j.ijmedinf.2012.10.007. 
[6] Jay. B. Barney, Gaining and Sustaining Competitive Advantage. USA: AddisonWesley Publishing Campany, 1997.

[7] P. Cannon and McCarthy, Manajemen Pemasaran. Jakarta: Salemba Empat, 2008.

[8] P. K. Edward, "Relations Industrielles," Ind. Relat. Employ. Relatsh., vol. 50, no. 1, pp. 39-65, 1995.

[9] M. E. Porter, Competitive Advantage: Creating and Sustaining Superior Performance, 1 edition. New York: Free Press, 1998.

[10] B. A. Widjaja, "Perencanaan Strategis Sistem Informasi / Teknologi Informasi di
PT. Miwon Indonesia," Program Pasca Sarjana Institut Teknologi Sepuluh Nopember, Surabaya, 2013.

[11] drg. Puti Aulia Rahma MPH, "Akreditasi Rumah Sakit, Pengakuan Atas Kualitas Layanan," Majalah Dental \& Dental Edisi September-Oktober, 2012.

[12] KARS, "Komisi Akreditasi Rumah Sakit," 2015. http://www.kars.or.id/ (accessed Mar. 20, 2017). 